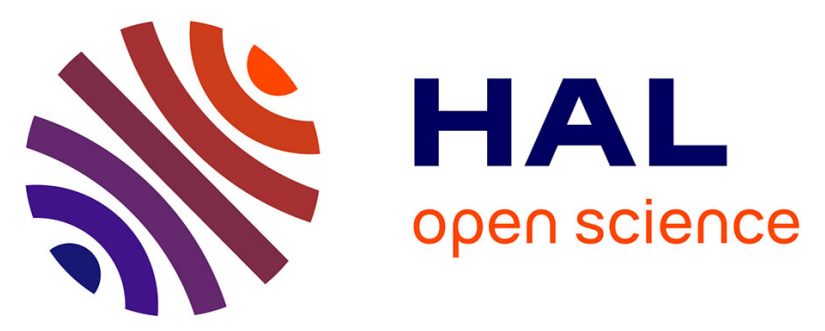

\title{
Lanthanide-mediated triangular cationic assemblies: structural and physico-chemical properties
}

Soumaila Zebret, Nathalie Dupont, Celine Besnard, Gérald Bernardinelli, Josef Hamacek

\section{- To cite this version:}

Soumaila Zebret, Nathalie Dupont, Celine Besnard, Gérald Bernardinelli, Josef Hamacek. Lanthanidemediated triangular cationic assemblies: structural and physico-chemical properties. Dalton Transactions, 2012, 41 (16), pp.4817. 10.1039/c2dt12227h . hal-02122895

\section{HAL Id: hal-02122895 \\ https://hal.science/hal-02122895}

Submitted on 3 Jun 2021

HAL is a multi-disciplinary open access archive for the deposit and dissemination of scientific research documents, whether they are published or not. The documents may come from teaching and research institutions in France or abroad, or from public or private research centers.
L'archive ouverte pluridisciplinaire HAL, est destinée au dépôt et à la diffusion de documents scientifiques de niveau recherche, publiés ou non, émanant des établissements d'enseignement et de recherche français ou étrangers, des laboratoires publics ou privés. 


\title{
Lanthanide-mediated triangular cationic assemblies: structural and physico-chemical properties $\uparrow$
}

\author{
Soumaila Zebret, ${ }^{a}$ Nathalie Dupont, ${ }^{b}$ Céline Besnard, ${ }^{c}$ Gérald Bernardinelli ${ }^{c}$ and Josef Hamacek ${ }^{* a}$
}

This contribution investigates $\mathrm{Ln}^{\mathrm{III}}$ complexes formed with a small ditopic ligand, $\mathbf{L 1}$, and their structural, thermodynamic and photophysical properties. The spectrophotometric and NMR titrations evidence the triangular assemblies $\left[\operatorname{Ln}_{3}(\mathbf{L} 1-\mathrm{H})_{3}\right]^{6+}$ at stoichiometric conditions and their properties are discussed in relation to $\mathbf{L 2}$-containing analogues. In addition, the dinuclear species, $\left[\operatorname{Ln}_{2}(\mathbf{L 1}-\mathrm{H})\right]^{5+}$, i s observed with an excess of metal.

\section{Introduction}

The number of specific applications of lanthanides in different domains of materials and life sciences ${ }^{1}$ is continuously growing. Although the starting materials are usually chosen from amongst the existing compounds, further optimization of molecular systems requires the fine tuning of the structure and, consequently, of their optical and paramagnetic properties. This is also the case of $\mathrm{Ln}^{\mathrm{III}}$-containing complexes applied in medical imaging and sensing. ${ }^{2}$ Starting with small, very stable mononuclear complexes with 1,4,7,10-tetraazacyclododecane- $N, N^{\prime}$, $N ", N "$-tetraacetic acid (DOTA) and diethylenetriaminepentaacetic acid (DTPA) derivatives, large polynuclear systems have been developed in order to improve, for instance, their relaxivity. ${ }^{3}$ Nowadays, there is a sizeable effort aimed at optimizing polynuclear complexes for multimodal applications, whereby a single molecule simultaneously integrates good relaxivity probes and optical or PET reporters. ${ }^{4}$ Nevertheless, this task remains challenging because of antagonistic coordination requirements for these imaging modes.

In order to develop multifunctional lanthanide-based devices, we have embarked on a project aimed at designing new organic receptors suitable for the preparation of multifunctional (e.g., heteronuclear) $\mathrm{Ln}^{\mathrm{III}}$ complexes. In addition to the family of tripodal ligands providing tetranuclear tetrahedral complexes, ${ }^{5}$ small ditopic ligands, L1 and L2 (Scheme 1), have been

${ }^{a}$ Department of Inorganic, Analytical and Applied Chemistry, University of Geneva, 30 quai E. Ansermet, 1211 Geneva 4, Switzerland. E-mail: Josef.Hamacek@unige.ch; Fax:+41-22-379-6830;.Tel: +41-22-3796413

${ }^{b}$ Department of Physical Chemistry, University of Geneva, 30 quai

E. Ansermet, 1211 Geneva 4, Switzerland

${ }^{c}$ Laboratory of Crystallography, University of Geneva, 24 quai

E. Ansermet, 1211 Geneva 4, Switzerland

$\dagger$ Electronic supplementary information (ESI) available: crystallographic data and figures showing the structure of $\mathbf{L 1}$ and $\left[\mathrm{Eu}_{3}(\mathbf{L} \mathbf{1}-\mathrm{H})_{3}\right]^{6+}$, the emission and excitation spectra, NMR titration and distribution curves. CCDC 854826-854828. For ESI and crystallographic data in CIF or other electronic format see DOI: $10.1039 / \mathrm{c} 2 \mathrm{dt} 12227 \mathrm{~h}$

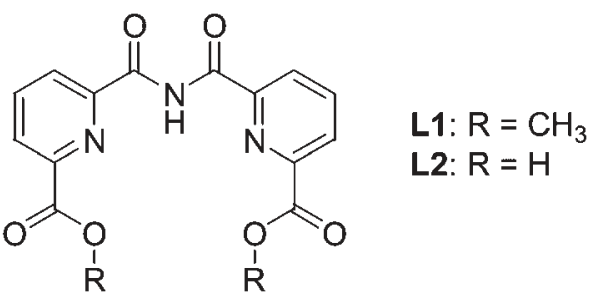

Scheme 1 The chemical structures of $\mathbf{L 1}$ and $\mathbf{L 2}$.

designed by attaching pyridyl chromophores to a $N$ - $\beta$-dicarbonyl moiety. This type of ligand is reminiscent of $\beta$-diketonate compounds known for their good sensitization of $\mathrm{Ln}^{\mathrm{III}}$ luminescence. Indeed, the $N$ - $\beta$-dicarbonyl moiety can complex $\mathrm{Ln}^{\mathrm{III}}$ in a bidentate fashion, but examples are rare. ${ }^{6}$ On the contrary, $\mathrm{Ln}^{\mathrm{III}}$ complexes involving two pyridyl moieties connected in this way have not been previously studied, although bis(2-pyridylcarbonyl)amine has already been applied in the complexation of transition metal ions. ${ }^{7}$

In our recent work, we have reported on the trinuclear complexes, $\mathbf{L n}_{3}(\mathbf{L} 2-3 \mathrm{H})_{3}{ }^{8,}{ }^{89}$ The crystal structures revealed their triangular topology, where three ligands are interconnected with three metal ions. Each metal ion is heptacoordinated and the two remaining positions are occupied by water molecules. However, this feature does not prevent the good sensitization of $\mathrm{Eu}^{\mathrm{III}}$ luminescence, which occurs due to the high conjugation over the ligand. ${ }^{8}$ On the other hand, the self-assembly of $\mathbf{L} 2$ with $\mathrm{Gd}^{\mathrm{III}}$ cations accumulates high amounts of paramagnetism and water relaxivity $\left(r_{1} \sim 9.5 \mathrm{~s}^{-1} \mathrm{mM}^{-1}\right.$ per Gd) is higher than, or comparable to, other complexes possessing two coordinated water molecules. ${ }^{10}$ However, a significant drawback of the trinuclear system is the relatively modest thermodynamic stability, which excludes these compounds from their immediate use in medical fields until a significant improvement in their stability can be achieved. Nevertheless, this interesting polynuclear system has the potential for further improvement of its properties.

Initially, the above-mentioned trinuclear $\mathrm{Eu}^{\mathrm{III}}$ and $\mathrm{Gd}^{\mathrm{III}}$ complexes have been prepared by lanthanide-assisted hydrolysis with 
Table 1 Crystallographic data and selected bond lengths

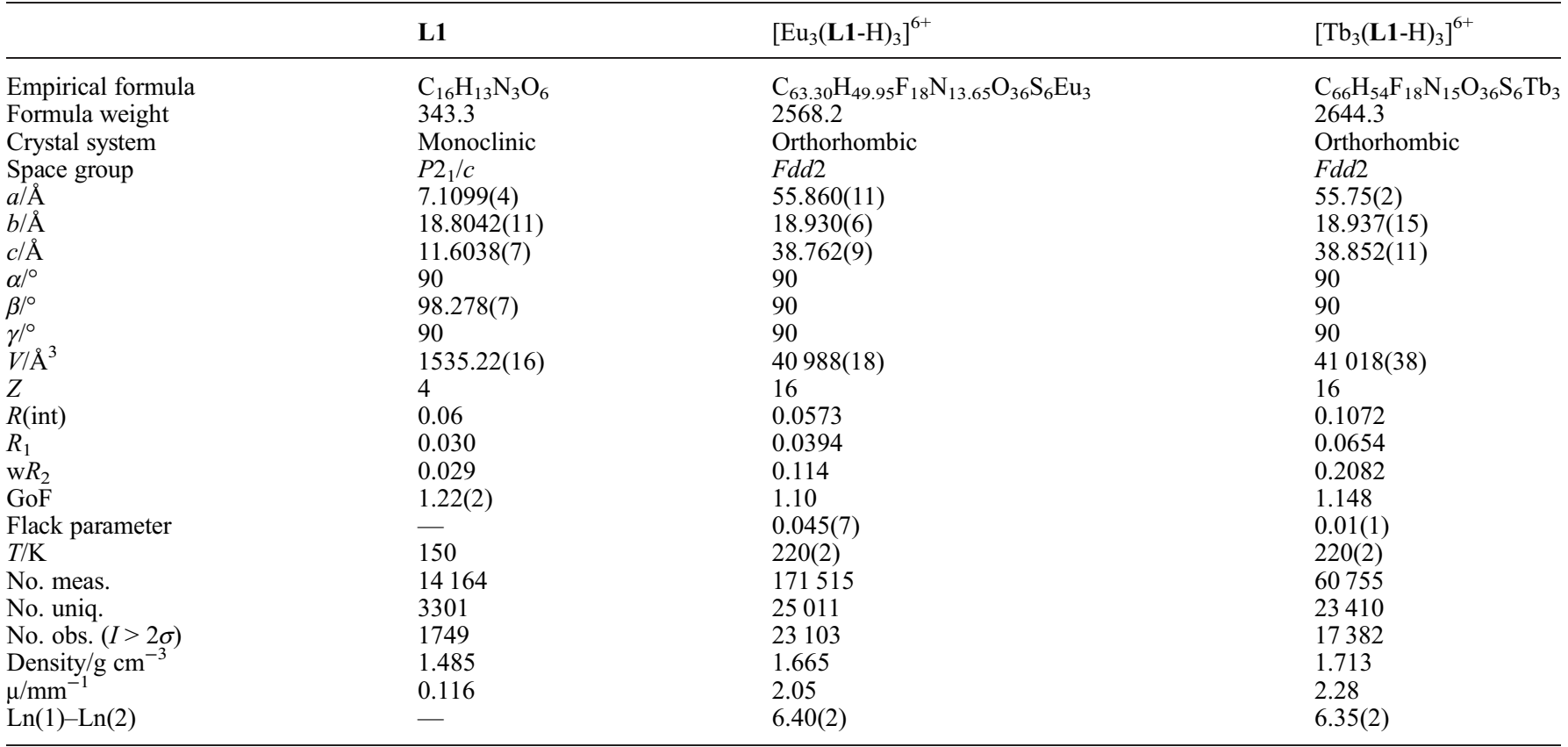

the methylester precursor, L1 ${ }^{8}$ However, free $\mathbf{L 2}$ could not be prepared from $\mathbf{L} \mathbf{1}$ by a simple hydrolysis of the ester groups due to the simultaneous attack of the central amide group. Consequently, the reaction of $\mathbf{L 2}$ with $\mathrm{Ln}^{\mathrm{III}}$ cannot be studied directly. Therefore, we report here on the formation and characterisation of $\mathrm{Ln}^{\text {III }}$ complexes with $\mathbf{L} \mathbf{1}$ in order to get insight into the speciation of $\mathrm{Ln}^{\text {III }}$ complexes with $N$ - $\beta$-dicarbonyl containing ligands, and to better understand this polynuclear system. The structural characterization of $\mathbf{L 1}$ and its lanthanide complexes has been completed by NMR, spectrophotometric and photophysical studies.

\section{Results and discussion}

\section{X-Ray crystal structure of L1}

The ligand $\mathbf{L 1}$ was prepared according to the previously described procedure. ${ }^{8}$ Its ${ }^{1} \mathrm{H}$ NMR spectrum in $\mathrm{CDCl}_{3}$ shows 5 signals, which is compatible with an average $C_{2 \mathrm{v}}$ symmetry. The recrystallisation of $\mathbf{L 1}$ from dichloromethane provides transparent crystals suitable for X-ray analysis. The refined parameters are summarized in Table 1 and the crystal structure of $\mathbf{L} \mathbf{1}$ is shown in Fig. 1. The diffraction data show an almost planar configuration of $\mathbf{L 1}$, whereby the planes defined by the two pyridines of $\mathbf{L} \mathbf{1}$ are slightly distorted by $14.6^{\circ}$. One ester group is almost coplanar with one pyridine ring $\left(5.1^{\circ}\right)$, while the second group is turned by $33.6^{\circ}$ (Fig. 1b) to minimize the dipole-dipole and steric interactions. The coordinating atoms of pyridine and the terminal carbonyl groups form a potentially pentadentate cavity. The amidic carbonyls are directed out of the cavity and potentially represent a bidentate site. The crystal packing (Fig. S1 $\dagger$ ) shows the stacking interactions between the almost parallel pyridine moieties of the neighbouring ligands with a distance of $3.35 \AA$.

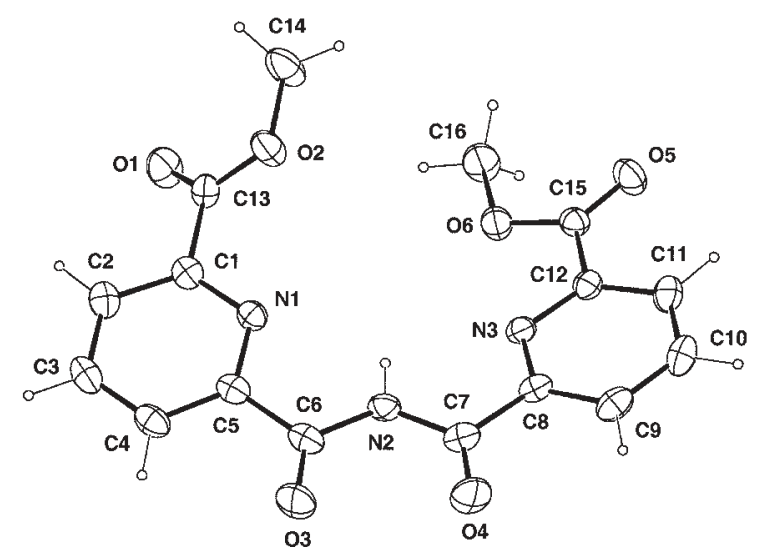

a)

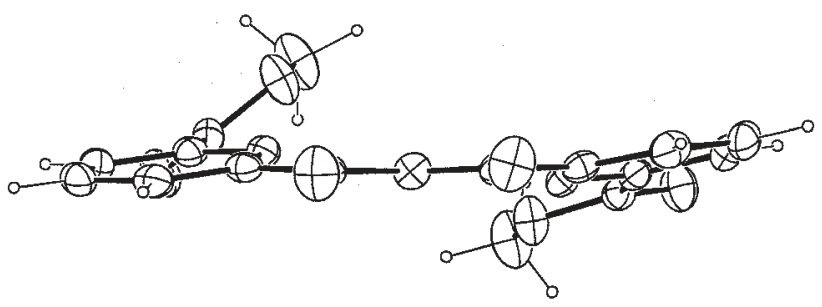

b)

Fig. 1 The X-ray crystal structure of L1. Front (a) and side (b) views.

\section{Preparation and characterization of $\mathrm{Ln}^{\mathrm{III}}$ complexes with $\mathrm{L} 1$ $(\mathbf{L n}=\mathbf{E u}, \mathbf{T b})$}

The lanthanide complexes with $\mathbf{L} \mathbf{1}$ are prepared by mixing equimolar amounts of lanthanide triflate salts and $\mathbf{L 1}$ in acetonitrile. The ${ }^{1} \mathrm{H}$ NMR spectrum of the Eu ${ }^{\text {III }}$ complex shows a significant 
<smiles>COC(=O)c1cccc(C(=O)NC(=O)c2cccc(C(=O)OC)n2)n1</smiles>
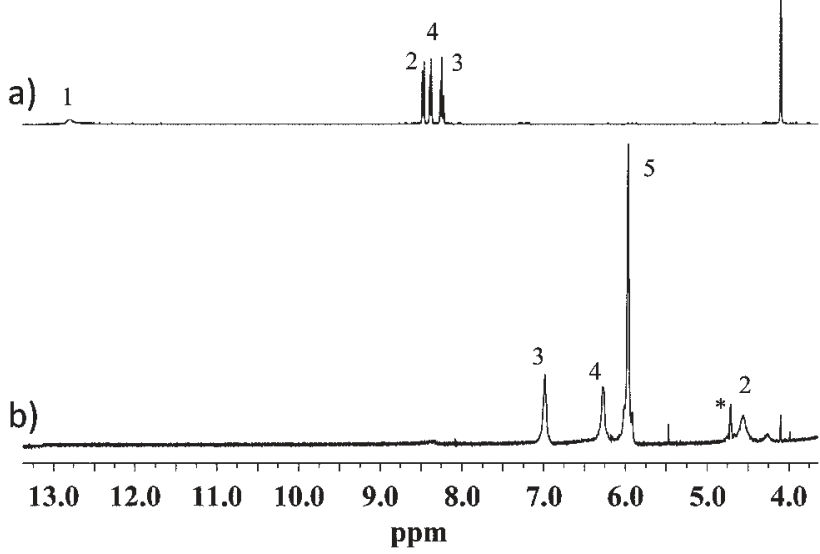

Fig. 2 The ${ }^{1} \mathrm{H}$ NMR spectra of $\mathbf{L 1}$ (a) and $\left[\mathrm{Eu}_{3}(\mathbf{L} \mathbf{1}-\mathrm{H})_{3}\right]^{6+}$ (b). The complex is formed upon the addition of 1 eq of $\mathrm{Eu}\left(\mathrm{CF}_{3} \mathrm{SO}_{3}\right)_{3}$ to $\mathbf{L 1}$. Small amounts of the second complex $(*)$ can be observed.

chemical shift of the ligand protons and the presence of four signals indicates a relatively high symmetry (Fig. 2). Indeed, the formation of the trinuclear complex, $\left[\mathrm{Eu}_{3}(\mathbf{L 1}-\mathrm{H})_{3}\right]^{6+}$, is confirmed by ESI-MS spectroscopy. The solid complexes were obtained by precipitation from their concentrated solutions. The off-white material is highly hygroscopic and difficult to isolate. Nevertheless, slow recrystallization from acetonitrile gives crystals suitable for X-ray crystallography. The direct addition of water to the solution of $\mathrm{Eu}_{3}(\mathbf{L} \mathbf{1}-\mathrm{H})_{3}\left(\mathrm{CF}_{3} \mathrm{SO}_{3}\right)_{6}$ rapidly provokes the complete decomplexation of the ligand, whose hydrolysis may then slowly occur.

\section{X-Ray crystal structure of $\mathrm{Ln}^{\mathrm{III}}$ complexes $(\mathrm{Ln}=\mathrm{Eu}, \mathrm{Tb})$}

The refinement of the crystallographic data shows the formation of trinuclear triangular complexes with both lanthanide cations. The isolated complexes are isostructural with similar cell volumes and differ only in the number of uncoordinated acetonitrile molecules included in the model. The obtained structural parameters for the $\mathrm{Eu}^{\mathrm{III}}$ and $\mathrm{Tb}^{\mathrm{III}}$ complexes are summarized in Table 1, but only the crystal structure of $\mathrm{Eu}_{3}(\mathbf{L 1}-\mathrm{H})_{3}\left(\mathrm{CF}_{3} \mathrm{SO}_{3}\right)_{6}$ is discussed in detail here (Fig. 3 and $\mathrm{S} 2 \dagger$ ). As expected, the complexes adopt a similar triangular topology as their analogues with L2. Three cations are interconnected by three ligands and form an equilateral triangle. The $\mathrm{Ln}^{\mathrm{III}}$ cations are globally ninecoordinated. The seven coordinating atoms come from the two L1 ligands and the two remaining positions are occupied by triflate anions. This compensates for the positive charge associated to lanthanides and allows the overall charge of the complex to be zero. The crystal structure data show an overall $C_{3 \mathrm{~h}}$ symmetry of the complex, which agrees well with the experimental ${ }^{1} \mathrm{H}$ NMR data.

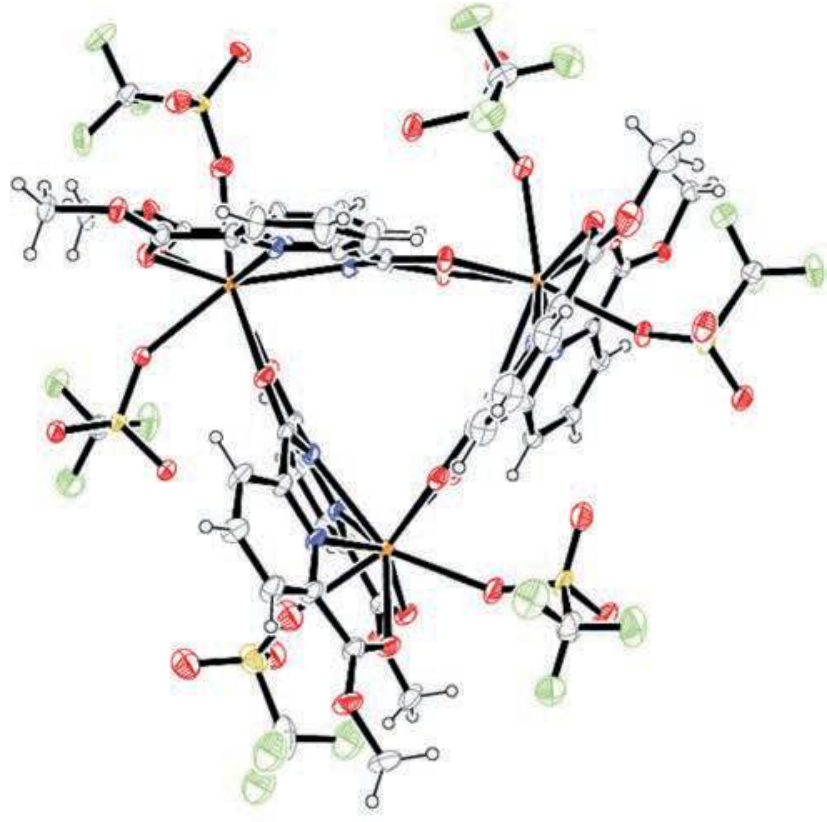

a)

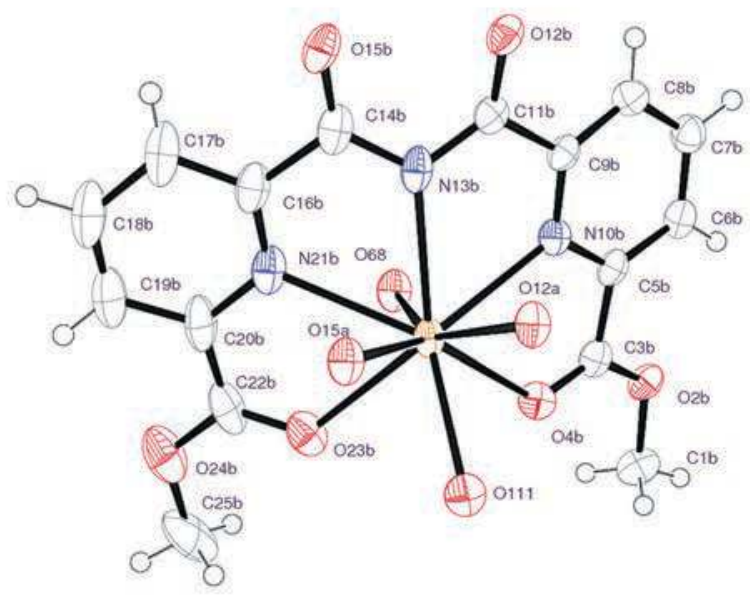

b)

Fig. 3 Crystal structure of $\mathrm{Eu}_{3}(\mathbf{L 1}-\mathrm{H})_{3}\left(\mathrm{CF}_{3} \mathrm{SO}_{3}\right)_{6}$. (a) The ORTEP view (50\% ellipsoid). (b) The detailed view of the $\mathrm{Eu}^{\text {III }}$ coordination sphere in the pentadentate cavity including atom numbering.

The coordination sphere can be described as a distorted monocapped tetragonal antiprism, whose base is composed of the three nitrogen atoms of $\mathbf{L} \mathbf{1}$ and one triflate oxygen $(\mathrm{N} 10 \mathrm{~b}, \mathrm{~N} 13 \mathrm{~b}$, $\mathrm{N} 21 \mathrm{~b}$ and $\mathrm{O} 68$ ). The second face is formed by two carboxylate (O4b and O23b) and two carbonyl oxygens (O12a and O15a). The capping oxygen $\mathrm{O} 111$ comes from the second triflate anion (Fig. 3b). The average intermetallic distance, $\mathrm{Eu}-\mathrm{Eu}$, is equal to 6.40 $\AA$. The coordination of $\mathrm{Ln}^{\text {III }}$ is accompanied by the rotation of the terminal carbonyl groups toward the metal ion. The ester groups are almost coplanar with the pyridine ring. Upon coordination with metal ions, the angle between the pyridine moieties of the same $\mathbf{L 1}$ ligand (between $140^{\circ}$ and $153^{\circ}$ ) decreases in comparison with free $\mathbf{L} 1\left(165.5^{\circ}\right)$, which suggests a larger bending angle of the complexed L1. Interestingly, the 


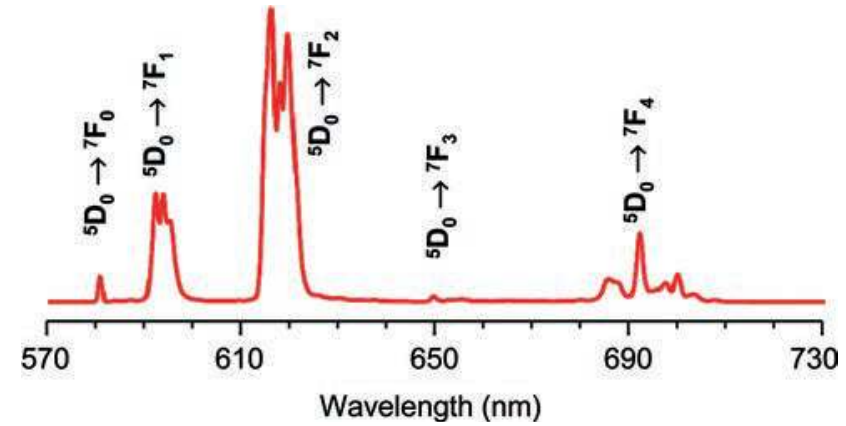

Fig. 4 The emission spectrum of $\mathrm{Eu}_{3}(\mathbf{L 1}-\mathrm{H})_{3}\left(\mathrm{CF}_{3} \mathrm{SO}_{3}\right)_{6}$ in the solid state measured at $10 \mathrm{~K}$ with an excitation wavelength $280 \mathrm{~nm}$.

coordination bonds with $\mathrm{Tb}^{\mathrm{III}}$ are, on average, shorter than with $\mathrm{Eu}^{\mathrm{III}}$, which translates to a slight shortening of the metal-metal distances in the $\mathrm{Tb}^{\mathrm{III}}$ complex with respect to the $\mathrm{Eu}^{\mathrm{III}}$ one (Table $\mathrm{S} 1 \dagger$ ). This contraction is illustrated by the superposition of both crystal structures in Fig. S3. $\uparrow$ Contrary to the L1 structure, hydrogen bonding and $\pi-\pi$ stacking interactions are missing in the crystal packing of the complexes (Fig. S4 $\dagger$ ).

\section{The photophysical properties of the $\mathrm{Eu}^{\mathrm{III}}$ complex}

The Eu ${ }^{\text {III }}$ complexes with L2 have excellent photophysical properties despite the presence of coordinated water molecules. ${ }^{8}$ Therefore, we were interested in the properties of the parent complexes with $\mathbf{L 1}$ in solution and in the solid state for the sake of comparison. Taking into consideration the hygroscopic properties of $\mathrm{Eu}_{3}(\mathbf{L 1}-\mathrm{H})_{3}\left(\mathrm{CF}_{3} \mathrm{SO}_{3}\right)_{6}$, the crystals were rapidly transferred from acetonitrile under an inert atmosphere into the spectrometer. The high-resolution emission spectrum of the $\mathrm{Eu}^{\mathrm{III}}$ complex is shown in Fig. 4. An analysis of the main Eu ${ }^{\mathrm{III}}$ transition bands shows three components for ${ }^{5} \mathrm{D}_{0} \rightarrow{ }^{7} \mathrm{~F}_{1}$, five for ${ }^{5} \mathrm{D}_{0} \rightarrow{ }^{7} \mathrm{~F}_{2}$ and nine components for ${ }^{5} \mathrm{D}_{0} \rightarrow{ }^{7} \mathrm{~F}_{4}$. This splitting pattern is the same as for $\mathrm{Eu}_{3}(\mathbf{L 2}-3 \mathrm{H})_{3}\left(\mathrm{H}_{2} \mathrm{O}\right)_{6}{ }^{8}$ and confirms the low local symmetry $\left(C_{\mathrm{s}}\right)$ of the $\mathrm{Eu}^{\mathrm{III}}$ coordination sphere.

As shown in Fig. $\mathrm{S} 5, \uparrow$ the resolution of the emission bands belonging to $\mathrm{Eu}_{3}(\mathbf{L} \mathbf{1}-\mathrm{H})_{3}\left(\mathrm{CF}_{3} \mathrm{SO}_{3}\right)_{6}$ depends on the temperature. Although the spectra exhibit similar shapes, a decrease in the emission intensity at room temperature is observed together with a concomitant band broadening associated with the amplification of molecular vibrations. The absence of structural changes with the temperature is confirmed by the fitted lifetimes, which do not significantly vary, and their average value is equal to $0.43(5) \mathrm{ms}$. Table 2 shows the lifetimes for three different emission wavelengths $(581,593$ and $616.5 \mathrm{~nm})$ as a function of temperature .

The excitation spectra recorded at $10 \mathrm{~K}$ show the same profile (Fig. S6 $†$ ), and a single peak is present for $\operatorname{Eu}\left({ }^{5} \mathrm{D}_{0} \leftarrow{ }^{7} \mathrm{~F}_{0}\right)$ at $580 \mathrm{~nm}$. This indicates that there is one type of Eu ${ }^{\mathrm{III}}$ coordination site in this compound. The energy of the $\operatorname{Eu}\left({ }^{5} \mathrm{D}_{0} \leftarrow{ }^{7} \mathrm{~F}_{0}\right)$ transitions depends on the composition of the coordination sphere and this value can be estimated using Frey and Horrocks equation (eqn (1)), ${ }^{11}$ in which $\tilde{v}_{0}=17374.0 \mathrm{~cm}^{-1}$ is the energy of the $\mathrm{Eu}\left({ }^{5} \mathrm{D}_{0} \leftarrow{ }^{7} \mathrm{~F}_{0}\right)$ transition in the free metal ion, $C_{\mathrm{CN}}$ is equal to 1.0 for the nine-coordinated $\mathrm{Eu}^{\mathrm{III}}$ cation, $n_{\mathrm{i}}$ is the
Table 2 The luminescence lifetimes as a function of temperature (10 $\left.300 \mathrm{~K}, \lambda_{\mathrm{ex}}=280 \mathrm{~nm}\right)^{a}$

\begin{tabular}{llll}
\hline Temperature $/ \mathrm{K}$ & $\tau_{581} / \mathrm{ms}$ & $\tau_{593} / \mathrm{ms}$ & $\tau_{616.5} / \mathrm{ms}$ \\
\hline 10 & 0.43 & 0.45 & 0.44 \\
77 & 0.42 & 0.44 & 0.42 \\
100 & 0.41 & 0.44 & 0.42 \\
150 & 0.40 & 0.42 & 0.40 \\
200 & 0.40 & 0.43 & 0.41 \\
250 & 0.41 & 0.45 & 0.44 \\
300 & 0.43 & 0.51 & 0.51 \\
& &
\end{tabular}

number of atoms of type ' $\mathrm{i}$ ' and $\delta_{\mathrm{i}}$ is the capacity of the atom, $\mathrm{i}$, to accept the electronic density of the metal ion.

$$
\tilde{v}=\tilde{v}_{0}+C_{\mathrm{CN}} \cdot \sum n_{\mathrm{i}} \delta_{\mathrm{i}}
$$

The coordination sphere is considered to be that shown by the crystal structure: two heterocyclic nitrogens $\left(\delta_{\mathrm{N}}=-15.3\right)$, the two oxygens of the ester groups $\left(\delta_{\text {Oester }}=-11.1\right)$, two amidic carbonyls $\left(\delta_{\text {Oamide }}=-15.7\right)$, one nitrogen $\left(\delta_{\mathrm{N}}-=-17.8\right)^{8}$ and two triflate oxygens. Since the value $\delta$ for the triflates is unknown, let's consider the value reported for the charged carboxylate oxygens $\left(\delta_{\mathrm{O}}=-17.2\right)^{11}$ as a reasonable approximation. The application of eqn (1) gives the value $17237.6 \mathrm{~cm}^{-1}$ $(580.1 \mathrm{~nm})$. The experimental position of the $\operatorname{Eu}\left({ }^{5} \mathrm{D}_{0} \rightarrow{ }^{7} \mathrm{~F}_{0}\right)$ transition was found to be $17223.7 \mathrm{~cm}^{-1}$ at $10 \mathrm{~K}$, which corresponds to $17235.6 \mathrm{~cm}^{-1}$ at $295 \mathrm{~K}$ by taking into account the temperature correction of $1 \mathrm{~cm}^{-1} / 24 \mathrm{~K} .{ }^{12}$ The latter value thus agrees well with the prediction, since such a small difference is lower than the width of the half-height of the excitation band $\left(30 \mathrm{~cm}^{-1}\right)$.

The luminescence properties of $\mathrm{Eu}_{3}(\mathbf{L 1}-\mathrm{H})_{3}\left(\mathrm{CF}_{3} \mathrm{SO}_{3}\right)_{6}$ dissolved in acetonitrile are similar to those found in the solid state. The related emission spectra are shown in Fig. $\mathrm{S} 7 \dagger$ and the lifetime is equal to $0.48(2) \mathrm{ms}$ at $298 \mathrm{~K}\left(\lambda_{\mathrm{ex}}=280 \mathrm{~nm}\right)$. Similar lifetimes are found for $\mathrm{Eu}{ }^{\mathrm{III}}$ complexes containing two coordinated water molecules, including the trinuclear complexes with L2. Consequently, this suggests the presence of two water (or solvent) molecules in the first coordination sphere instead of triflates. The absolute quantum yield for $\left[\mathrm{Eu}_{3}(\mathbf{L} \mathbf{1}-\mathrm{H})_{3}\right]^{6+}$ in acetonitrile amounts to $4.8 \%$. This value is about three times lower compared to the analogous complexes with $\mathbf{L} \mathbf{2}$ in water, but it remains a respectable yield measured for an unsaturated complex. For a solution concentration of $\sim 10^{-4} \mathrm{M}$, the distribution of the species, which can be calculated using the HySS program and the stability constants (vide infra), show an almost quantitative presence of the trinuclear complex (91\%) and, thus, it has the main contribution to the quantum yield.

\section{Speciation of the Eu ${ }^{\text {III }}-\mathrm{L} 1$ system with NMR and spectrophotometry}

To yield global information about the Eu ${ }^{\text {III }}-\mathbf{L 1}$ system, the speciation of the Eu ${ }^{\text {III }}$ complexes was investigated with ${ }^{1} \mathrm{H}$ NMR. The solutions with different $[\mathrm{Eu}] /[\mathbf{L 1}]$ ratios were prepared in $\mathrm{CD}_{3} \mathrm{CN}$ and allowed to equilibrate. The observed spectral 
variations are given in Fig. S8.† With the stepwise addition of $\mathrm{Eu}^{\mathrm{III}}$, the ligand peaks decrease (see for instance the amide proton at $13 \mathrm{ppm}$ ) and a new set of peaks emerge until about 1 equivalent has been added. This first complex is related to the stoichiometry $[\mathrm{Eu}] /[\mathbf{L 1}]=1$ and corresponds to the trinuclear species, $\left[\mathrm{Eu}_{3}(\mathbf{L} \mathbf{1}-\mathrm{H})_{3}\right]^{6+}$, which has been previously characterized by NMR and crystallography. Further metal additions provoke the formation of a new species that becomes dominant in an excess of metal.

The second complex is almost quantitatively formed at three equivalents of europium. The resolution of the peaks in the ${ }^{1} \mathrm{H}$ NMR spectrum increases with the addition of the metal, which improves the metal-ligand exchange and points to the unsaturated character of this complex. In order to match the observed high symmetry (one set of signals), we suggest the formation of a dinuclear complex, where one metal ion is coordinated to the pentadentate site and the second is coordinated to the bidentate site with the carbonyl groups. Moreover, a significant upfield shift of all the proton signals is apparently induced by an additional of the $\mathrm{Eu}^{\mathrm{III}}$ cation. Nevertheless, the presence of the presumed dinuclear complex, $\left[\operatorname{Eu}_{2}(\mathbf{L 1}-\mathrm{H})\right]^{5+}$, could not be confirmed with ES-MS measurements due to its relative fragility and a likely easy dissociation in the electrospray. The relative evolution of the species is illustrated with a qualitative distribution diagram tracing the selected peak area $v s$. the $[\mathrm{Eu}] /[\mathbf{L 1}]$ ratio (Fig. 5).

The spectrophotometric titrations of $\mathbf{L} \mathbf{1}$ with $\mathrm{Ln}^{\mathrm{III}}$ triflates $(\mathrm{Eu}$ or $\mathrm{Tb}$ ) were carried out in dry acetonitrile and the metal salts were added up to three equivalents. A significant increase in the absorbance between 255 and $330 \mathrm{~nm}$ with a concomitant bathochromic shift is observed in the course of the titration (Fig. 6). This is attributed to the combination of $n \rightarrow \pi^{*}, \pi \rightarrow \pi^{*}$ and intramolecular charge transfer ${ }^{13}$ transitions due to the extended conjugation upon coordination with $\mathrm{Eu}^{\mathrm{III}}$. Additionally, it confirms the implication of both the sites in the complexation. During the titration, two clear isosbestic points are observed. The first one, at $228 \mathrm{~nm}$, indicates the equilibrium between L1 and the first complex. The second point at $256 \mathrm{~nm}$ corresponds to the equilibrium between the first and the second complex. Finally, the statistical treatment of the spectrophotometric data

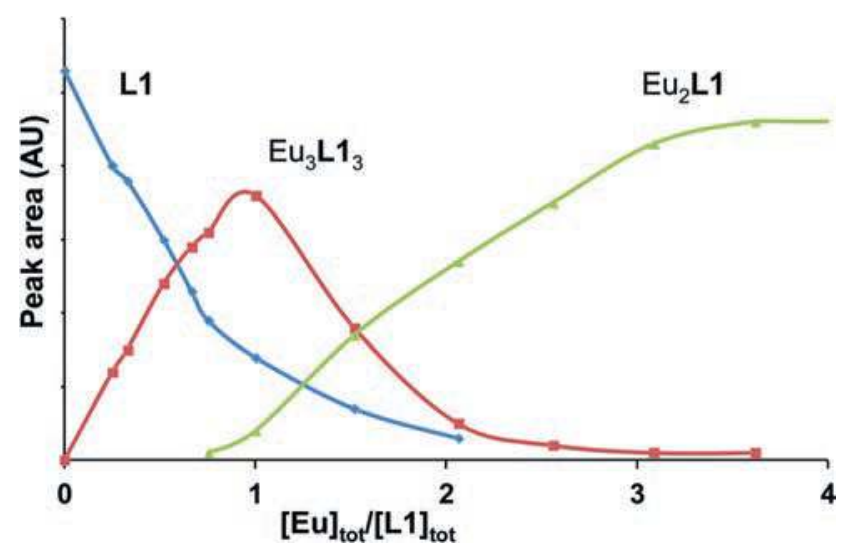

Fig. 5 An experimental distribution diagram for the Eu ${ }^{\text {III }}-\mathbf{L 1}$ complexes along the ${ }^{1} \mathrm{H}$ NMR titration. The peak area of the methylester protons $(\mathrm{H} 5)$ vs. the $[\mathrm{Eu}] /[\mathbf{L 1}]$ ratio. confirms the formation of a trinuclear species at an equimolar ratio and a dinuclear complex in an excess of metal, according to the equilibria described in equations (2) and (3). This model is in agreement with the NMR titration and the fitted stability constants are summarized in Table 3.

$$
\begin{gathered}
3 \mathrm{Ln}(\mathrm{III})+3 \mathbf{L 1} \stackrel{\beta_{\mathrm{Ln}_{3} \mathbf{L 1}_{3}}}{\longleftarrow}\left[\operatorname{Ln}_{3}(\mathbf{L} \mathbf{1}-\mathrm{H})_{3}\right]^{6+} \quad \beta_{\mathrm{Ln}_{3} \mathbf{L} \mathbf{1}_{3}} \\
2 \mathrm{Ln}(\mathrm{III})+\mathbf{L 1} \stackrel{\beta_{\mathrm{Ln}_{2} \mathbf{L} 1}}{\longleftarrow}\left[\operatorname{Ln}_{2}(\mathbf{L} \mathbf{1}-\mathrm{H})\right]^{5+} \quad \beta_{\mathrm{Ln}_{2} \mathbf{L} \mathbf{1}}
\end{gathered}
$$

The variation of the $\mathrm{Eu}^{\mathrm{III}}$ species concentration calculated with the fitted stabilities is given in Fig. S9. $\dagger$ The distribution curves are closely related to the experimental curves obtained with the NMR titration (Fig. 5). The fitted electronic spectra of the complexes are given in Fig. 6b. It is worth noting that the trinuclear species with $\mathbf{L 1}$ has an absorption profile similar to the analogous trimetallic complex with $\mathbf{L 2}$, which indicates similar energy levels within both complexes.

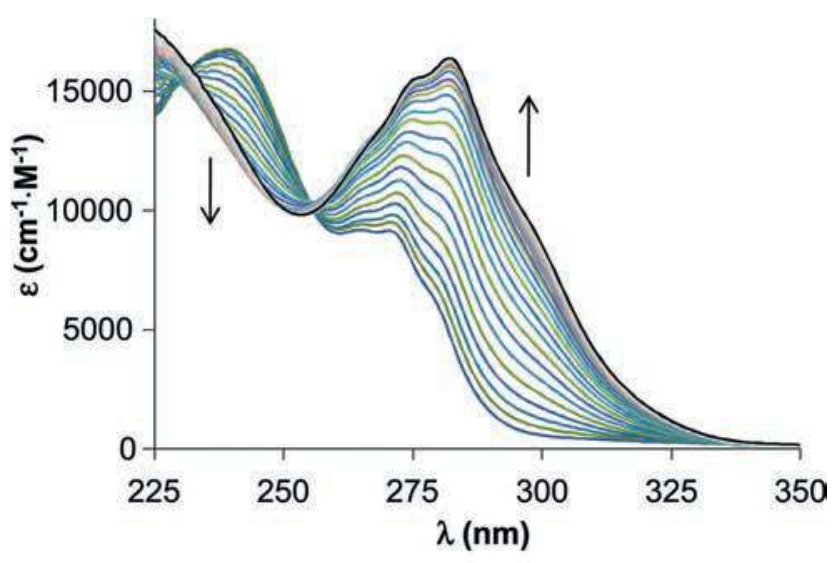

a)

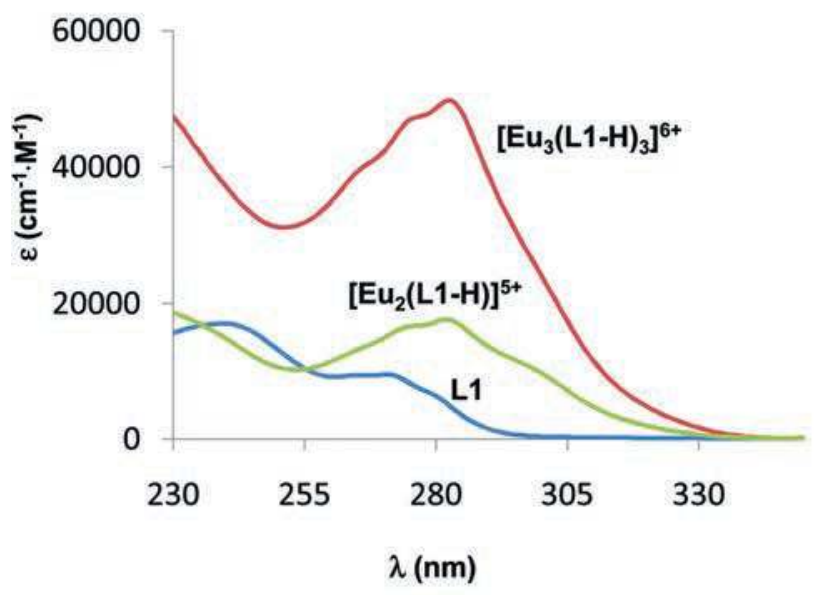

b)

Fig. 6 (a) The variation of the absorption spectra for the titration of $\mathbf{L} 1$ with $\mathrm{Eu}^{\text {III }}$. (b) The calculated electronic spectra of the species observed within the titration. 
Table 3 Stability constants for the $\mathrm{Ln}^{\mathrm{III}}$ complexes with $\mathbf{L} 1$ (spectrophotometry, acetonitrile, $298 \mathrm{~K}$ )

\begin{tabular}{lll}
\hline & $\log \beta_{\mathrm{Ln}_{2} \mathbf{L 1}}$ & $\log \beta_{\operatorname{Ln}_{3} \mathbf{L} \mathbf{1}_{3}}$ \\
\hline $\mathrm{Eu}$ & $9.3(1)$ & $24.7(1)$ \\
$\mathrm{Tb}$ & $9.4(2)$ & $25.1(2)$ \\
\hline
\end{tabular}

\section{Conclusions}

The coordination behaviour of $\mathbf{L 1}$ in the presence of $\mathrm{Ln}^{\mathrm{III}}$ has been investigated by means of classical physico-chemical methods (NMR, ES-MS and spectrophotometry). The X-ray data allow the molecular structure of $\mathbf{L} \mathbf{1}$ to be established and explicitly confirm the formation of the $\left[\operatorname{Ln}_{3}(\mathbf{L} 1-H)_{3}\right]^{6+}$ complex expected for $[\operatorname{Ln}] /[\mathbf{L 1}]=1: 1$. Due to the intrinsic ligand preorganization, the metal ions are easily complexed in the pentadentate binding site. The isolated Eu ${ }^{\text {III }}$ triangular complex has similar photophysical properties to the complex with $\mathbf{L 2}$, except it has a lower quantum yield. In an excess of the metal, speciation studies reveal the formation of a new, probably dinuclear, complex where two metal ions are bound to both the coordinating segments of L1. The stability constants of the trinuclear complexes are relatively modest because of an incomplete charge compensation.

\section{Experimental}

\section{Solvents and starting materials}

These were purchased from Acros Organics or Sigma-Aldrich and used without further purification unless otherwise stated. The perchlorate lanthanide salts were prepared from the corresponding oxides (Aldrich, 99.99\%) and dried according to the published procedures. The $\mathrm{Ln}^{\mathrm{III}}$ content of the solid salts was determined by complexometric titrations with Titriplex III (Merck) in the presence of urotropine and xylene orange. The ligand, L1, was prepared according to the published procedure. ${ }^{8}$ The crystals that were suitable for diffraction measurements were obtained by slow cooling of a hot dichloromethane solution of L1.

Synthesis of $\mathrm{Ln}^{\mathrm{III}}$ complexes with $\mathrm{L1}(\mathrm{Ln}=\mathrm{Eu}$ or $\mathrm{Tb})$. The lanthanide complexes were prepared by mixing the lanthanide triflate salts with $\mathbf{L 1}$ in acetonitrile. The precipitated compounds were recrystallized from hot acetonitrile.

$\mathbf{E u}_{3}(\mathbf{L 1}-\mathbf{H})_{3}\left(\mathbf{C F}_{3} \mathbf{S O}_{3}\right)_{6} \cdot{ }^{1} \mathrm{H}$ NMR $\left(\mathrm{CD}_{3} \mathrm{CN}\right): \delta=6.99(\mathrm{t}, 2 \mathrm{H}$, $\mathrm{CH}), 6.28(\mathrm{~d}, 2 \mathrm{H}, \mathrm{CH}), 5.96\left(\mathrm{~s} 6 \mathrm{H}, \mathrm{CH}_{3},\right), 4.56(\mathrm{~s}, 2 \mathrm{H}, \mathrm{CH})$ ppm. ESI-MS $\left(\mathrm{CH}_{3} \mathrm{CN}\right): \mathrm{m} / z$ calcd for $\left[\mathrm{Eu}_{3}(\mathbf{L 1}-\mathrm{H})_{3}\left(\mathrm{CF}_{3} \mathrm{SO}_{3}\right)_{5}\right]^{+}$: 2228.11; found 2227.75. Calcd for $\left[\mathrm{Eu}_{3}(\mathbf{L 1}-\mathrm{H})_{3}\left(\mathrm{CF}_{3} \mathrm{SO}_{3}\right)_{4}\right]^{2+}$ : 1039.52; found 1039.8. Calcd for $\left[\mathrm{Eu}_{3}(\mathbf{L 1}-\mathrm{H})_{3}\left(\mathrm{CF}_{3} \mathrm{SO}_{3}\right)_{3}\right]^{3+}$ : 643.3; found 643.9 .

Details about the refinement of the crystallographic data for $\mathrm{Ln}_{3}(\mathrm{L1}-\mathrm{H})_{3}\left(\mathrm{CF}_{3} \mathrm{SO}_{3}\right)_{6} \cdot x \mathrm{CH}_{3} \mathrm{CN}(\mathrm{Ln}=\mathrm{Eu}, \mathrm{Tb})$. Among the six triflate molecules, two are disordered. One was refined with two components, sharing an oxygen atom (O135), using restrains on the distances and anisotropic displacement parameters. The occupancies of each group were refined, their sum being constrained to one. The second one (containing S991 and S201) was refined using two components that were regularized and refined as a rigid body. For this position, the description of the disorder is not optimal, as shown by the small density peaks still present in the last difference Fourier map and the strong restrains and constrains (EADP on $\mathrm{F}$ and $\mathrm{O}$ atoms) that had to be applied to the displacement parameters in order to get the refinement to converge. For the Tb complex, two acetonitrile solvent molecules are included in the model and the rest of the solvent molecules are taken into account by the Squeeze/bypass procedure. ${ }^{14} \mathrm{~A}$ higher quality of data for the Eu complex allowed a better modelling so that the solvent was modelled using eight acetonitrile molecules, seven of them being not fully occupied. However, not all the solvent molecules have been found and there are still small voids in the structure and some remaining density that can be attributed to acetonitrile molecules with very weak occupancies. They were not included in the model since this did not significantly improve the fit.

Photophysical measurements. The emission and excitation spectra of the powder samples were measured on a Horiba Fluorolog 3 instrument with an excitation wavelength of $270 \mathrm{~nm}$. In order to exclude second order light from the excitation wavelength, a cut-off filter at $536 \mathrm{~nm}$ was used. Luminescence lifetimes were measured by exciting the powder samples at $355 \mathrm{~nm}$ with a pulsed $\mathrm{Nd}$ ): YAG laser (Quantel Brilliant, $7 \mathrm{~ns}$ pulse width). The measuring time corresponded to the deactivation time of the sample. The obtained signal was then integrated. The detection system consisted of a Spex 270M monochromator, a Hamamatsu photomultiplier and a Stanford research system SR 400 photon counter. The luminescence spectra and decay profiles in solution were recorded with a Perkin-Elmer LS-50 spectrometer. The quantum yield of $\mathrm{Eu}_{3}(\mathbf{L 1}-\mathrm{H})_{3}\left(\mathrm{CF}_{3} \mathrm{SO}_{3}\right)_{6}$ in acetonitrile has been calculated according to the equation $\Phi_{\mathrm{x}} / \Phi_{\mathrm{r}}$ $=\left(A_{\mathrm{r}}(\tilde{v}) I_{\mathrm{r}}(\tilde{v}) n_{\mathrm{x}}^{2} D_{\mathrm{x}}\right) /\left(A_{\mathrm{x}}(\tilde{v}) I_{\mathrm{x}}(\tilde{v}) n_{\mathrm{r}}^{2} D_{\mathrm{r}}\right)$, where ' $\mathrm{x}$ ' refers to the sample and ' $\mathrm{r}$ ' to the reference (a solution of $\left[\mathrm{Eu}(\text { terpy })_{3}\right]^{3+}$ in acetonitrile, $\left.\Phi_{\mathrm{abs}}=1.3 \%\right){ }^{15} \mathrm{~A}$ is the absorbance, $\tilde{v}$ is the excitation wavenumber used, $I$ is the intensity of the excitation light at this energy, $n$ is the refractive index and $D$ is the integrated emitted intensity.

Spectrophotometric titration. These were performed with a J\&M diode array spectrometer (Tidas series) using Hellma optodes (optical path length: $0.1 \mathrm{~cm}$ ) immersed in a thermostated titration vessel $(293 \mathrm{~K}) .20 \mathrm{ml}$ of $\mathbf{L 1}\left(3.00 \times 10^{-4} \mathrm{M}\right)$ dissolved in acetonitrile was titrated with $\mathrm{Ln}^{\mathrm{III}}$ triflate acetonitrile solutions $\left(\sim 2.4 \times 10^{-3} \mathrm{M}\right)$ using an automatic burette setup (Metrohm). The mathematical treatment of the spectrophotometric titrations was performed with the SPECFIT program. ${ }^{16}$ The distribution curves were calculated with the HySS program. ${ }^{17}$

\section{Acknowledgements}

Financial support from the University of Geneva and SNF is gratefully acknowledged. We thank Prof. A. Hauser for providing access to the spectroscopy equipment. 


\section{References}

1 Lanthanide Probes in Life, Chemical and Earth Sciences, ed. J.-C. G. Bünzli and G. R. Choppin, Elsevier, The Netherlands, 1989.

2 The Chemistry of Contrast Agents in Medical Magnetic Resonance Imaging, ed. A. E. Merbach, E. Tóth, John Wiley \& Sons, Ltd., 2001.

3 (a) G. M. Nicolle, E. Toth, H. Schmidtt-Willich, B. Radüchel and A. Merbach, Chem.-Eur. J., 2002, 8, 1040-1048; (b) J. B. Livramento, L. Helm, A. Sour, C. O'Neil, A. E. Merbach and E. Toth, Dalton Trans., 2008, 1195-1202; (c) J. B. Livramento, A. Sour, A. Borel, A. E. Merbach and E. Toth, Chem.-Eur. J., 2006, 12, 989-1003; (d) T. N. Parac-Vogt, L. Vander Elst, K. Kimpe, S. Laurent, C. Burtea, F. Chen, R. Van Deun, Y. Ni, R. N. Muller and K. Binnemans, Contrast Media Mol. Imaging, 2006, 1, 267-278.

4 (a) A. Keliris, T. Ziegler, R. Mishra, R. Pohmann, M. G. Sauer, K. Ugurbil and J. Engelmann, Bioorg. Med. Chem., 2011, 19, 25292540; (b) H. C. Manning, T. Goebel, R. C. Thompson, R. R. Price, H. Lee and D. J. Bornhop, Bioconjugate Chem., 2004, 15, 1488-1495.

5 (a) J. Hamacek, G. Bernardinelli and Y. Filinchuk, Eur. J. Inorg. Chem., 2008, 3419-3422; (b) J. Hamacek, C. Besnard, T. Penhouet and P.Y. Morgantini, Chem.-Eur. J., 2011, 17, 6753-6764; (c) B. El Aroussi, L. Guénée, P. Pal and J. Hamacek, Inorg. Chem., 2011, 50, 8588-8597.

6 M. Ferbinteanu, T. Kajiwara, K.-Y. Choi, H. Nojiri, A. Nakamoto, N. Kojima, F. Cimpoesu, Y. Fujimura, S. Takaishi and M. Yamashita, J. Am. Chem. Soc., 2006, 128, 9008.
7 (a) D. Marcos, R. Martinez-Manez, J. V. Folgado, A. Beltran-Porter and D. Beltran-Porter, Inorg. Chim. Acta, 1989, 159, 11-18; (b) H. Tanaka, T. Kajiwara, Y. Kaneko, S. Takaishi and M. Yamashita, Polyhedron, 2007, 26, 2105-2109; (c) D. C. d. C. Gomes, L. M. Toma, H. O. Stumpf, H. Adams, J. A. Thomas, F. Lloret and M. Julve, Polyhedron, 2008, 27, 559-573.

8 S. Zebret, N. Dupont, G. Bernardinelli and J. Hamacek, Chem.-Eur. J., 2009, 15, 3355-3358.

9 S. Zebret, E. Torres, E. Terreno, L. Guénée, C. Senatore and J. Hamacek, Dalton Trans., 2011, 40, 4284-4290.

10 (a) P. Caravan, J. J. Ellison, T. J. McMurry and R. B. Lauffer, Chem. Rev., 1999, 99, 2293-2352; (b) The Chemistry of Contrast Agents in Medical Magnetic Resonance Imaging, ed. A. E. Merbach, E. Tóth, John Wiley \& Sons, Ltd, 2001.

11 S. T. Frey and W. d. Horrocks, Inorg. Chim. Acta, 1995, 229, 383.

12 M. Albin and W. D. Horrocks Jr., Inorg. Chem., 1985, 24, 895.

13 L. Wasylina, E. Kucharska, Z. Weglinski and A. Puszko, Chem. Heterocycl. Compd., 1999, 35, 186-194.

14 A. L. Spek and P. van der Sluis, Acta Crystallogr., Sect. A: Found. Crystallogr., 1990, A46, 194-201.

15 S. Petoud, J.-C. G. Bünzli, C. Piguet, Q. Xiang and R. Thummel, J. Lumin., 1999, 82, 69-79.

16 H. Gampp, M. Maeder, C. J. Meyer and A. D. Zuberbuehler, Talanta, 1986, 33, 943-951.

17 L. Alderighi, P. Gans, A. Ienco, D. Peters, A. Sabatini and A. Vacca, Coord. Chem. Rev., 1999, 184, 311-318. 